\title{
Performance of uniform and heterogeneous slip distributions for the modeling of the November 2016 off Fukushima earthquake and tsunami, Japan
}

\author{
Kenji Nakata ${ }^{1 *} \mathbb{B}$, Yutaka Hayashi ${ }^{2}$, Hiroaki Tsushima ${ }^{3}$, Kenichi Fujita ${ }^{1}$, Yasuhiro Yoshida ${ }^{4}$ and Akio Katsumata ${ }^{1}$
}

\begin{abstract}
The $M_{w} 6.9$ earthquake off Fukushima Prefecture, Japan, of 22 November 2016 was followed by a tsunami that struck the Japanese coast from Hokkaido in northern Japan to Wakayama Prefecture in western Japan. We compared the performance of a seismologically deduced single-fault model, a seismologically deduced finite fault slip model (FFM), an optimized single-fault model based on tsunami data, the FFM with horizontal shift, and the tsunami waveform inversion models of the previous studies considered for this earthquake regarding reproduction of tsunami waves by tsunami computations. It is important to discuss how these models work well because it is sometimes desirable to obtain an earthquake source model to estimate tsunami waves with a simple process obtained with limited data from the viewpoint of tsunami prediction. The seismologically deduced FFM has an advantage in terms of the information of slip regions of fault plane and was superior to the seismologically deduced single-fault model, especially in predicting amplitudes of tsunami waves. This means that when only with seismic data, the FFM could narrow the range of forecast of tsunami amplitude. In the comparison of models optimized with tsunami data, the single-fault model showed the almost equivalent performance of the tsunami waveform inversion models of previous studies regarding the waveform coincidence with observations and the horizontal location at the negative peak of the initial sea surface displacement. In case the main generation region of the tsunami is concentrated in one place, the tsunamis can be expressed by a single-fault model by conducting the detailed grid search. We also confirmed that the centroid location of centroid moment tensor (CMT) solution and the absolute location of the FFM were not necessarily suitable to express tsunamis, while the moment magnitude, the focal mechanism, the centroid depth of CMT solution, and the relative slip distribution of the FFM were effective to represent tsunamis. Since this event occurred at the shallow depth, the speed of tsunami wave is particularly slow. Therefore, it would be advisable to pay attention to the horizontal uncertainty to apply seismologically obtained solution to tsunami forecast, especially when a tsunami occurs in shallow water.
\end{abstract}

Keywords: 2016 off Fukushima earthquake, Tsunami, Tsunami computation, Uniform single-fault model, Seismologically deduced finite fault slip model

\footnotetext{
*Correspondence: knakata@mri-jma.go.jp

${ }^{1}$ Meteorological Research Institute, Japan Meteorological Agency, 1-1

Nagamine, Tsukuba, Ibaraki 305-0052, Japan

Full list of author information is available at the end of the article
} 


\section{Introduction}

After an earthquake of moment magnitude $\left(M_{w}\right) 6.9$ occurred beneath the Pacific Ocean off Fukushima Prefecture, Japan, on 22 November 2016 at 05:59 JST (UTC + 09:00), tsunamis were observed from Hokkaido in northern Japan to Wakayama Prefecture in western Japan. The maximum amplitude of the tsunami was $1.4 \mathrm{~m}$ at Sendai Port in Miyagi Prefecture (JMA 2016a). According to the Japan Meteorological Agency (JMA), this was a normal faulting event that occurred in the crust of the North American plate above its boundary with the Pacific plate (JMA 2016a). Its epicenter was about $50 \mathrm{~km}$ off the coast. Direct waves as well as reflected waves from the coast of Fukushima Prefecture were observed along the coast of Miyagi Prefecture (JMA 2017a). The distribution of aftershocks from this event defined an east-dipping fault plane (Headquarters for Earthquake Research Promotion 2016; Toda and Goto 2016).

Fujii and Satake (2016) and Gusman et al. (2017a) simulated the tsunami from this event using a single-fault model with a size of $20 \times 10 \mathrm{~km}$. Gusman et al. (2017a) and Adriano et al. (2018) estimated the tsunami source by inversion of the tsunami waveforms. Suppasri et al. (2017) conducted tsunami computations using 15-m-resolution topographic data and compared their results with data from field surveys. While the previous studies specified various wave source models, the question remains whether how the models obtained from the data limited to seismic waves could work, and how much performance a simple uniform single-fault model can have for a complicated model, which have heterogeneous slip distribution, in this event. It is important to discuss such models' performances because it is sometimes desirable to obtain an earthquake source model to estimate tsunami waves with a simple process obtained with limited data from the viewpoint of tsunami prediction.

JMA utilizes an immediate centroid moment tensor (CMT) solution for an immediate tsunami forecast (Kamigaichi 2015). In that case, a uniform single-fault model is used since the slip distribution on the fault plane is unavailable in short duration soon after occurrence of the earthquake. Gusman et al. (2017a) pointed out that it was difficult to represent tsunami observation waveforms at all stations used for the tsunami source estimation with the single-fault model even if the size of the slip region of the model is adjusted. However, the optimum horizontal position of the model was not discussed in Gusman et al. (2017a). The distribution of slip on the fault plane, which is directly related to the area of tsunami generation, can be obtained as a finite fault slip model (FFM) estimated only with seismic waveforms (e.g., Yoshida et al. 2011; Iwakiri et al. 2014) as well as tsunami waveform inversion. Even though this event was relatively small, of magnitude 7 class, the FFM was obtained (JMA 2017b). So far, there have been studies on the use of FFM models for magnitude 8 class earthquakes to predict tsunami (e.g., Heidarzadeh et al. 2017; Gusman et al. 2017b). In those cases, the coastal grid intervals used for the tsunami computation were not so fine probably because of the long wavelength of tsunami waves considered. For the magnitude 7 class earthquakes, there have been few studies on the performance of the FFM by the comparison of tsunami waveforms.

In this study, we compared the performance of five models: the seismologically deduced single-fault model, the seismologically deduced FFM, the optimized singlefault model with tsunami waveform data, the FFM with horizontal shift, and the tsunami waveform inversion models of the previous studies. First, tsunami prediction by a single-fault model by CMT solution was compared with that by a seismologically deduced FFM. Next, an optimum single-fault model and the optimum FFM with horizontal shift were obtained using tsunami waveform data. Finally, the performances of models in this study were compared with that of the tsunami waveform inversion models of previous studies.

\section{Methodology and data \\ Single-fault model}

The single-fault model is parameterized by fault length, fault width, fault depth, slip amount, horizontal location, strike, dip, and rake. When the fault length and width are unknown, as is often the case in an immediate analysis soon after an earthquake occurrence, they are determined by a scaling law from the earthquake magnitude (e.g., Tanioka et al. 2017). In this study, we used the scaling law proposed by Utsu (2001):

$$
\log _{10} S=M_{w}-4.0
$$

where $S=L W$ is the fault area $\left(\mathrm{km}^{2}\right)$, based on fault length $L$ and fault width $W$, and $M_{w}$ is the moment magnitude. Given $M$ and assuming $W=L / 2$, this equation yields $S$, $L$, and $W$. This relation predicts the aftershock area well (Utsu 2001) and is used to calculate a synoptic image of the rupture zone under the assumption of a constant stress drop of $3 \mathrm{MPa}$ (Kikuchi 2003). When the slip distribution can be derived from other information such as tsunami data, $L$ and $W$ can be determined directly from it.

The average slip amount is obtained from the seismic moment and fault area according to Aki (1966):

$$
M_{0}=\mu D S
$$

where $M_{0}$ is the seismic moment, $\mu$ is the shear modulus of the rocks, and $D$ is the average slip amount. The moment magnitude $M_{w}$ (Kanamori 1977) is 


$$
M_{w}=\frac{\log M_{0}-9.1}{1.5} .
$$

$D$ is commonly calculated by assuming a certain value of $\mu$. In this study, $\mu$ is assumed to be $30 \mathrm{GPa}$ at a depth of about $10 \mathrm{~km}$ on the basis of the Preliminary Reference Earth Model (Dziewonski and Anderson 1981).

The strike, dip, slip angle, and midpoint depth of the fault were taken from the CMT solutions released by various institutions (Table 1). The horizontal location was determined from the distribution of aftershocks that occurred during the first hour after the earthquake.

\section{Seismologically deduced FFM (finite fault slip model)}

The seismologically deduced FFM models an earthquake fault as a set of small sub-faults, each with its own slip amount and slip history. The FFM used in this study is based on analysis of teleseismic body waves. The analysis starts by assuming a fault plane (often specified from the CMT solution) and an initial rupture starting point (typically the hypocenter). The parameters are estimated from the time-series waveform at seismic observation stations at teleseismic distances of $30^{\circ}-100^{\circ}$. In this study, which assumed that a high-quality FFM is obtained in real time, we used the FFM released by the JMA (JMA 2017b) about 1 month after the earthquake. (The FFM gave $M_{w}$ 7.2, which was larger than the $M_{w} 6.9-7.0$ given by CMT analyses.) The horizontal location of the FFM was not adjusted in use for the tsunami computation.

\section{Tsunami observation data}

The computed tsunami waveforms were compared with waveforms observed at the 13 coastal tide gauge stations and offshore GPS buoys (Kato et al. 2000; Kawai et al. 2012) shown in Fig. 1. The tidal component was removed from the observations by subtracting the theoretical values calculated by superposition of trigonometric functions (e.g., Murakami 1981).

\section{Tsunami computation and bathymetry data}

The tsunami computation relies on solving nonlinear long-wave equations with a staggered leapfrog

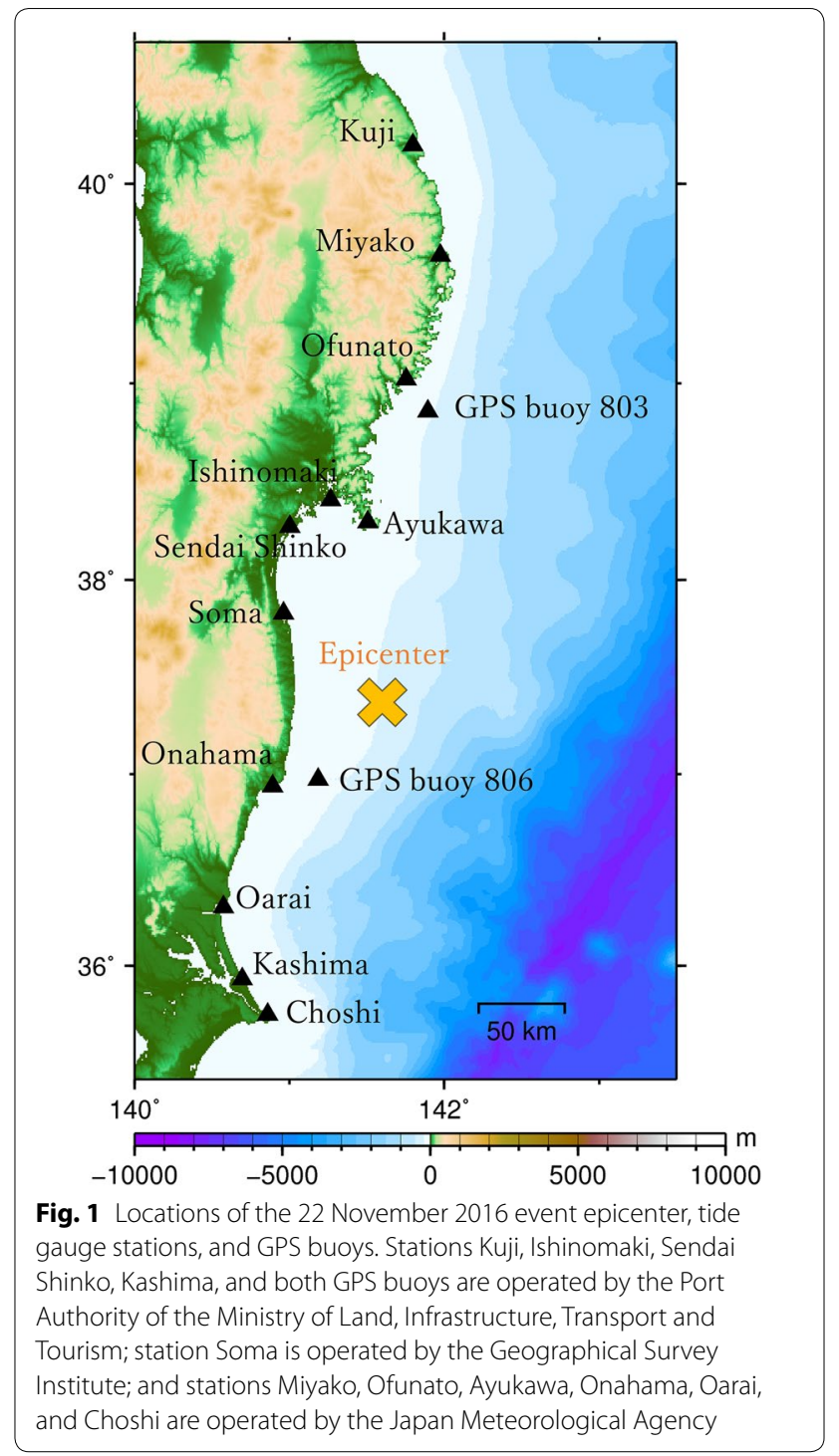

finite-difference scheme. The TUNAMI code (e.g., Imamura 1995; Goto et al. 1997) was used, with input/output modifications by the Meteorological Research Institute. Crustal deformation at the seafloor is calculated by the method of Mansinha and Smylie (1971) on the basis of

Table 1 East-dipping CMT solutions for the 22 November 2016 event from various institutions

\begin{tabular}{|c|c|c|c|c|c|c|c|}
\hline Source & Latitude ( $\left.{ }^{\circ} \mathrm{N}\right)$ & Longitude ( $\left.{ }^{\circ} \mathrm{E}\right)$ & Depth (km) & Strike & Dip & Rake & $M_{w}$ \\
\hline NIED (2016) & 37.3547 & 141.6042 & 11 & $47^{\circ}$ & $38^{\circ}$ & $-90^{\circ}$ & 7.0 \\
\hline JMA (2016b) & 37.18 & 141.6 & 10 & $45^{\circ}$ & $55^{\circ}$ & $-93^{\circ}$ & 6.9 \\
\hline JMA (2016c) & 37.22 & 141.6 & 12 & $65^{\circ}$ & $55^{\circ}$ & $-69^{\circ}$ & 6.9 \\
\hline USGS (2016) & - & - & 11.4 & $42^{\circ}$ & $49^{\circ}$ & $-101^{\circ}$ & 6.9 \\
\hline GCMT (2016) & 37.32 & 141.53 & 12 & $45^{\circ}$ & $41^{\circ}$ & $-95^{\circ}$ & 6.9 \\
\hline
\end{tabular}


fault parameters set by a single-fault model or an FFM. The tsunami computation assumes that the seafloor deformation instantaneously displaces the sea surface to the same extent.

For the bathymetry data, we used the gridded data set of the Cabinet Office Central Disaster Management Council of Japan (Cabinet Office 2003). The nested grid system was used as well as Gusman et al. (2017a) and Adriano et al. (2018). The computation proceeded from the coarsest to the finest grid interval $(1350 \mathrm{~m}, 450 \mathrm{~m}$, $150 \mathrm{~m}, 50 \mathrm{~m}$ ) for successively smaller domains, from the ocean to the vicinity of tide gauge stations (Fig. 2). The waveform at each tide gauge station was computed with a $50 \mathrm{~m}$ grid interval. While the construction works have been done since 2003 when the data set was made, the noticeable change in coastal structures near the tide gauge stations blocking the arrival of the tsunami was not seen at the bathymetry of $50 \mathrm{~m}$ grid interval, compared with the images from the Google Earth (https:// www.google.co.jp/earth/). Coastal structures in this data set, such as levees, are defined in terms of the boundaries

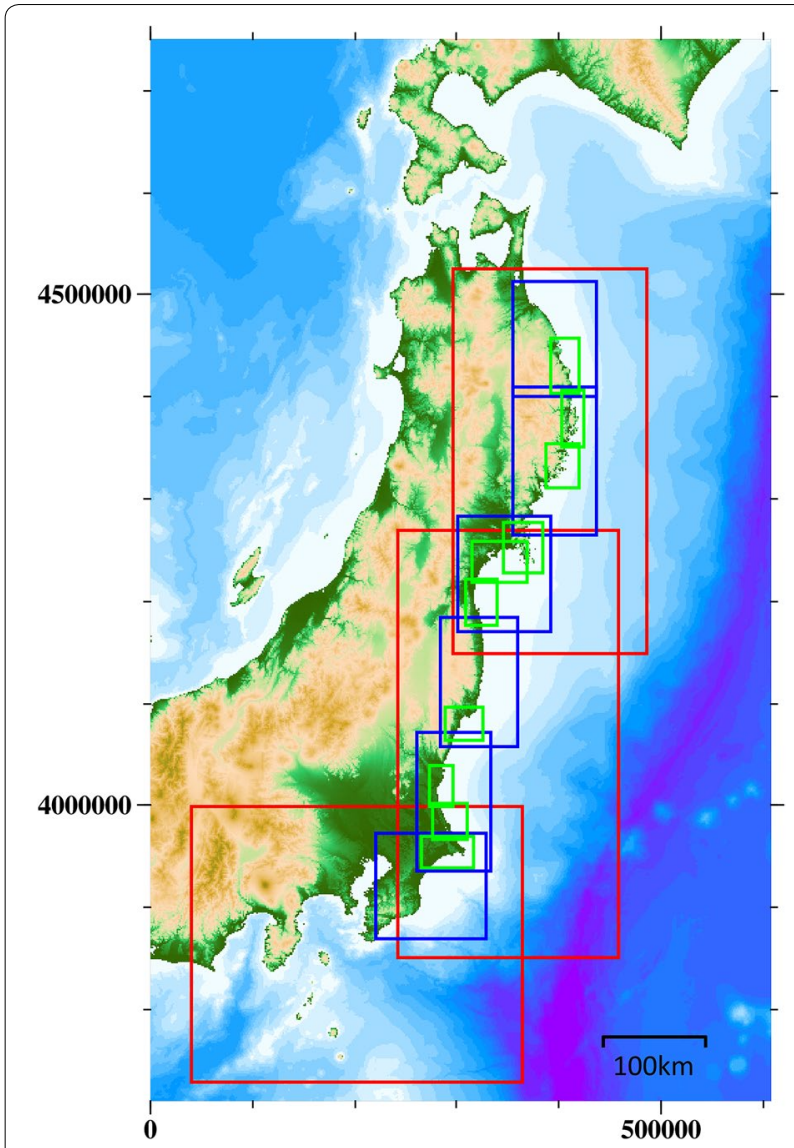

Fig. 2 The nested grid system used in this study. Red square frame indicates the computation area at $450 \mathrm{~m}$ grid intervals, blue $150 \mathrm{~m}$, green $50 \mathrm{~m}$ of $50 \mathrm{~m}$ grid cells. For convenience, if a coastal structure was indicated on either the north or east side of a cell, the elevation of the cell was replaced by the elevation of the coastal structure.

\section{Measurement of amplitude and period}

The amplitude and period of the first wave cycle were used to compare the computed and observed waveforms. Because the main effect of this normal faulting event was subsidence of the seafloor, we measured the pulling wave as the first wave cycle, ignoring the weak push wave that preceded it.

\section{Waveform coincidence score}

To quantify the degree of coincidence between the computed and observed waveforms, we relied on the variance reduction (VR) score. This score is often used for quality control of CMT solutions (e.g., Usui et al. 2010) and for evaluating tsunami waveform predictions (Tsushima et al. 2009). It is defined as:

$$
\mathrm{VR}=1-\frac{\int_{0}^{T}\left[o_{i}(t)-s_{i}(t)\right]^{2} \mathrm{~d} t}{\int_{0}^{T} o_{i}(t)^{2} \mathrm{~d} t}
$$

where $o_{i}(t)$ and $s_{i}(t)$ are the $i$ th observed and theoretical waveforms, respectively, and $T$ is the data length of the waveform used for analysis. VR has a value of 1 if the waveforms are perfectly matched and decreases as the difference between the waveforms increases.

We determined VR on the basis of two different data lengths. In one (VR1), only the first wave cycle was compared, and in the other (VR2), the full waveform from the first wave cycle to 9:00 JST on 22 November 2016 was compared.

\section{Results}

Tsunami computation by seismologically deduced single-fault model and FFM

We compared the observations of the 22 November 2016 tsunami to the waveforms computed by the single-fault model from the earthquake scaling law (model A) and the FFM based on seismic data (model B), as described in the "Methodology and data" section. Model A used the CMT solution from the National Research Institute for Earth Science and Disaster Resilience (NIED 2016), $M_{w} 6.9$ (Table 1), and the fault parameters are listed in Table 2. Figure 3 shows the initial sea surface displacement of the tsunami under both models, and Fig. 4 shows the observed and computed waveforms at each station.

Model B contains a region of strong local subsidence that does not appear in model $\mathrm{A}$, which reflects a region of large slip on the fault plane (Fig. 3). A comparison of 
Table 2 Model fault parameters

\begin{tabular}{|c|c|c|c|c|c|c|c|c|c|c|}
\hline Source model & Lat. $\left({ }^{\circ} \mathrm{N}\right)$ & Long. $\left({ }^{\circ} \mathrm{E}\right)$ & Depth (km) & Length (km) & Width (km) & Slip (m) & Strike & Dip & Rake & $M_{w}$ \\
\hline A (single-fault) & 37.26 & 141.45 & 11 & 40 & 20 & 1.2 & $47^{\circ}$ & $38^{\circ}$ & $-90^{\circ}$ & 6.9 \\
\hline B FFM & \multicolumn{9}{|c|}{ Multiple faults (JMA 2017b) } & 7.2 \\
\hline C (optimized single-fault) & 37.28 & 141.45 & 11 & 20 & 10 & 5.6 & $47^{\circ}$ & $38^{\circ}$ & $-90^{\circ}$ & 6.95 \\
\hline D (optimized FFM) & \multicolumn{9}{|c|}{ Model B shifted horizontally } & 7.2 \\
\hline
\end{tabular}

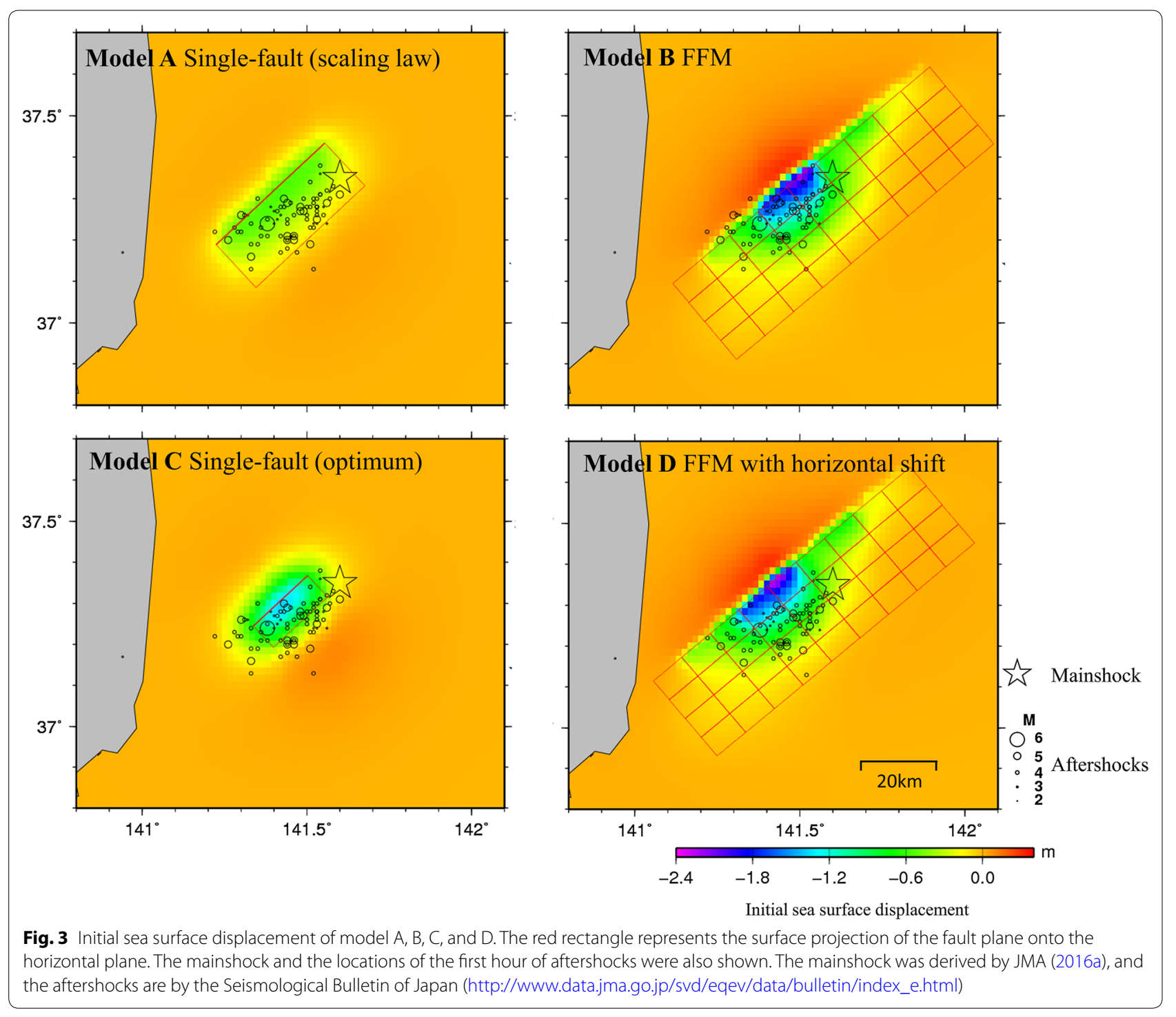

computed and observed waveforms shows that model B more closely approximated the observed amplitudes than model A (Fig. 4).

Values of VR1 for model A were consistently positive for all stations (Fig. 5). This means that defining the horizontal fault location from the area of immediate aftershocks that occurred during the first hour after the earthquake led to good phase matching of tsunami waves. VR1 values for model B were higher than those for model $\mathrm{A}$ at stations near the epicenter, but much lower at more distant stations. The main reason for this pattern is that the waveform phases (arrival 

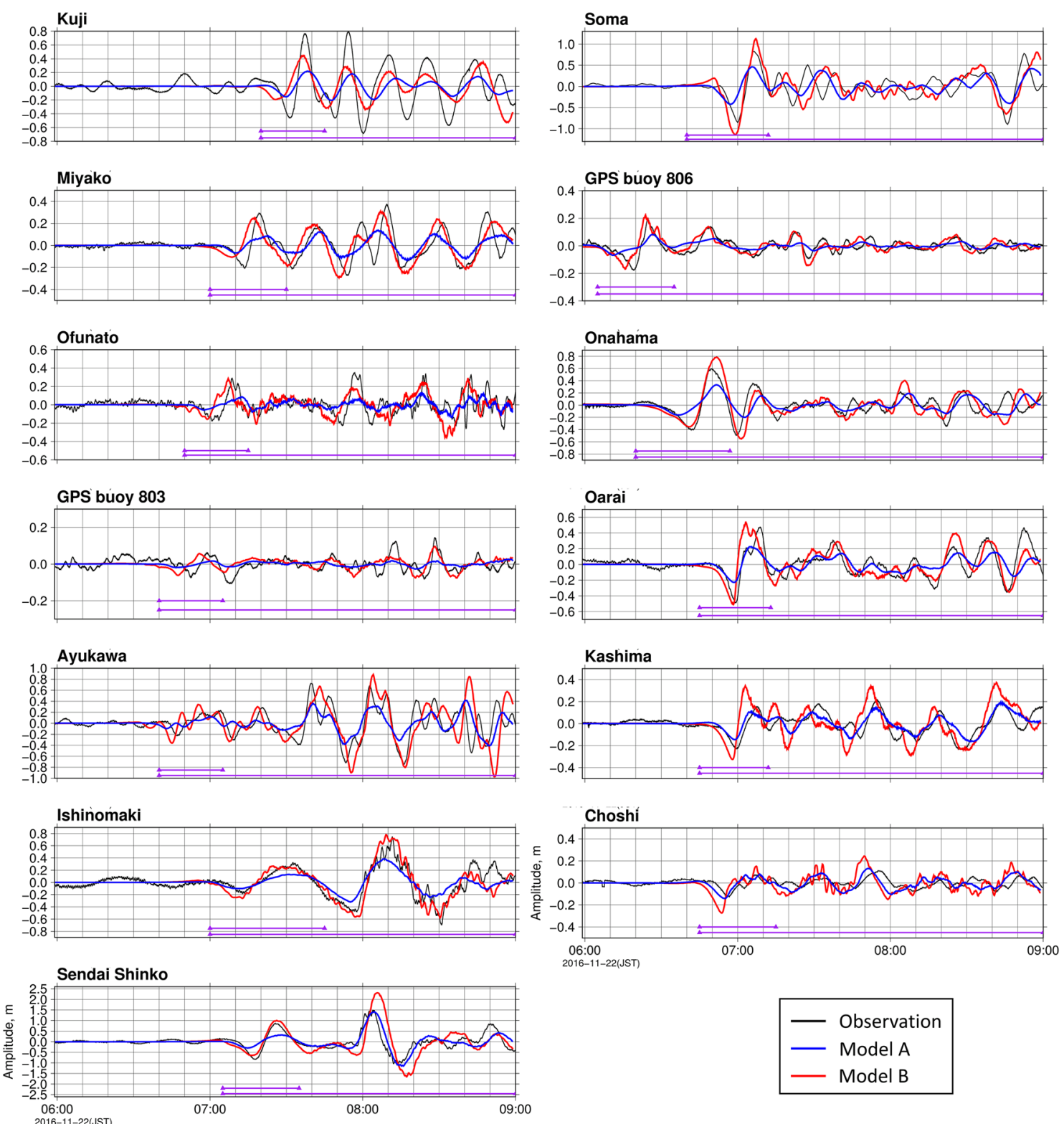

Fig. 4 Comparison of waveforms at 13 stations from observations, model A, and model B. Tsunami waveforms at tide gauge stations and GPS buoys (locations in Fig. 1). Black curves are the observed waveforms, blue curves are waveforms from model A, and red curves are waveforms from model B. Data lengths for calculating VR1 and VR2 at each station are indicated by purple lines

times) did not match between the observations and computations.

\section{Optimization of single-fault model based on tsunami data}

We performed a grid search to find an optimal singlefault model based on tsunami data. To obtain an optimal single-fault model as a tsunami source, we examined various values of fault length $L$, fault width $W$, slip amount $D$, moment magnitude $M_{w}$, horizontal location, and focal depth. Candidate values were 30,25 , and $20 \mathrm{~km}$ for $L ; 20$,
15 , and $10 \mathrm{~km}$ for $W ; 6.8-7.1$ for $M_{w}$; and $37.24-37.29^{\circ} \mathrm{N}$ and $141.42-141.47^{\circ} \mathrm{E}$ for the fault midpoint. Here, $D$ determined from $M_{w}$ was restricted to less than $10 \mathrm{~m}$ so as to be consistent with the maximum slip of the small fault segments in the FFM. Other parameters were the same as in model A. The parameters that maximized the value of VR1 for all 13 stations (0.82 median, 0.76 mean) were as follows: location $37.28^{\circ} \mathrm{N}, 141.50^{\circ} \mathrm{E}, L=20 \mathrm{~km}$, $W=10 \mathrm{~km}$, and $M_{w}=6.95$. These were adopted in the optimized single-fault model (model C). The determined 

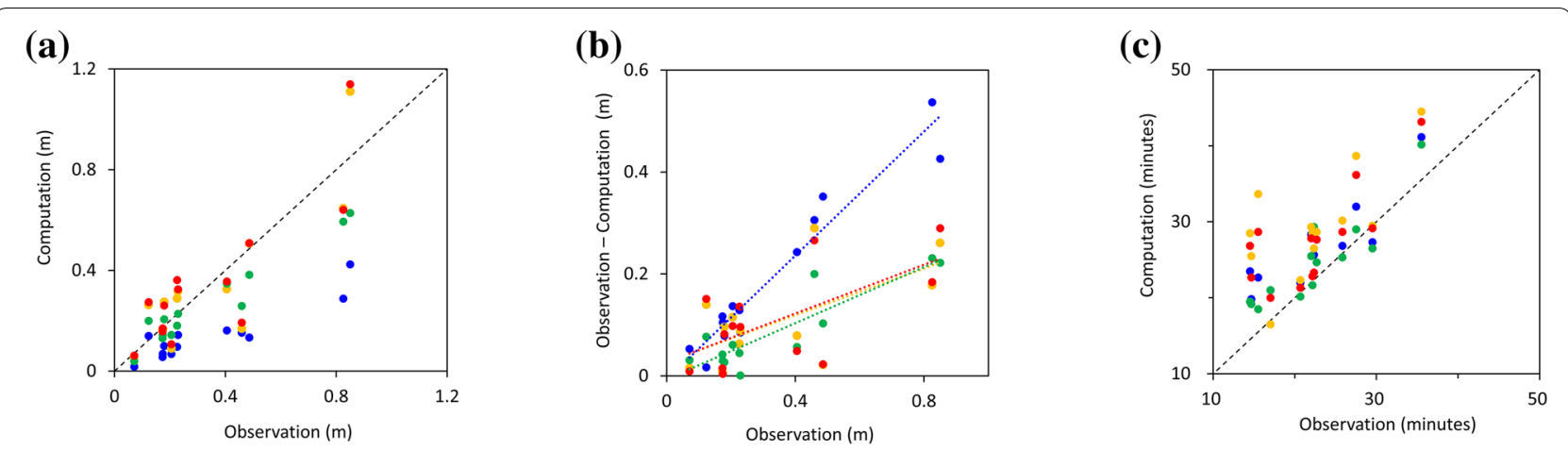

(d)

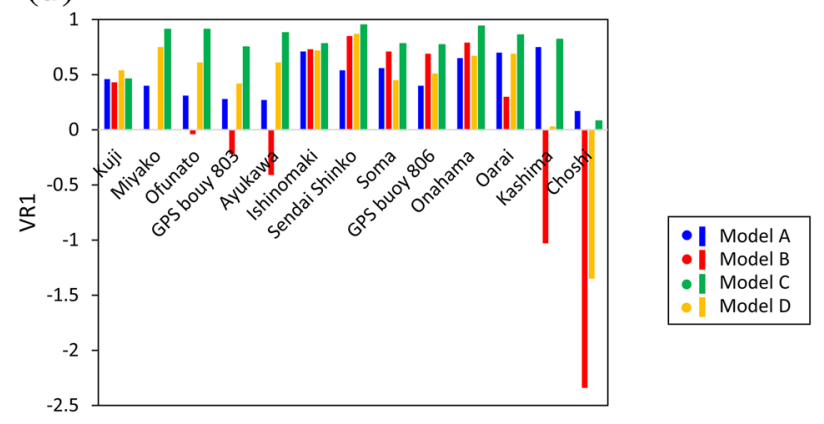

Fig. 5 Comparison of models A, B, C, and D at 13 stations. a Absolute amplitudes of the first pulling tsunami wave cycle. $\mathbf{b}$ Difference between the absolute amplitude of the computation and that of the observation. $\mathbf{c}$ Periods of the first wave cycle. $\mathbf{d} \vee \mathrm{VR} 1$. The dotted lines in $\mathbf{b}$ represent approximate best-fit curves

location was about $20 \mathrm{~km}$ away from the centroid location of used CMT solution. Figure 6 shows details of this optimization for the horizontal fault location (Fig. 6a); $L$, $W$, and $M_{w}$ (Fig. 6b); and fault depth (Fig. 6c). In particular, the depth was optimal around $10 \mathrm{~km}$, showing that the assumed depth for the initial model (given with reference to centroid depth of CMT solution) was reasonable. The initial sea surface displacement and the computed tsunami waveforms from model $\mathrm{C}$ are shown in Figs. 3 and 7, and the parameters are listed in Table 2. VR1 values showed that the computed and observed waveforms agreed well (Fig. 5). As a result of the relocation, it produced wave periods closer to the observations than those from models A and B, and the VR1 values became acceptable for all stations, including the distant ones. The region of slip on the fault plane from model $\mathrm{C}$ was about half the size estimated from the earthquake scaling law of Utsu (2001).

\section{FFM with horizontal shift}

We improved the horizontal fault location produced by the FFM to fit the observed tsunami waveforms through a grid search that first shifted model B horizontally at intervals of $0.05^{\circ}$ and then refined the grid search at $0.01^{\circ}$ intervals while keeping the slip distribution unchanged.
The number of computations was $30(6 \times 5)$ for $0.05^{\circ}$ and $80(8 \times 10)$ for $0.01^{\circ}$.

In the resulting model, model $\mathrm{D}$, the VR1 value was positive for all but one station (Fig. 5) when the original FFM was shifted $0.02^{\circ}$ to the north and $0.06^{\circ}$ to the west (Fig. 8). The VR2 values show the same tendency as the VR1 values. The computed waveform is compared with observations in Fig. 7. The mean VR1 value for all 13 stations improved from a median of 0.30 and a mean of 0.04 with the original FFM to a median of 0.61 and a mean of 0.42 with model D. It thus was more advantageous to use a horizontally shifted FFM to compute this tsunami. The $0.06^{\circ}$ (about $6 \mathrm{~km}$ ) shift is within the range of sub-fault size of $10 \mathrm{~km}$.

\section{Discussion}

\section{Comparison of single-fault models and FFMs}

In the comparison with the single-fault model by scaling law (model A), the FFM (model B) is advantageous because it has the information of the slip distribution of the fault plane. In fact, the model B better represented the amplitude than model A (Fig. 5b). Tsunami amplitude is the most important factor for tsunami forecast. When only with seismic data, the FFM could narrow the range of forecast of the tsunami amplitude. 


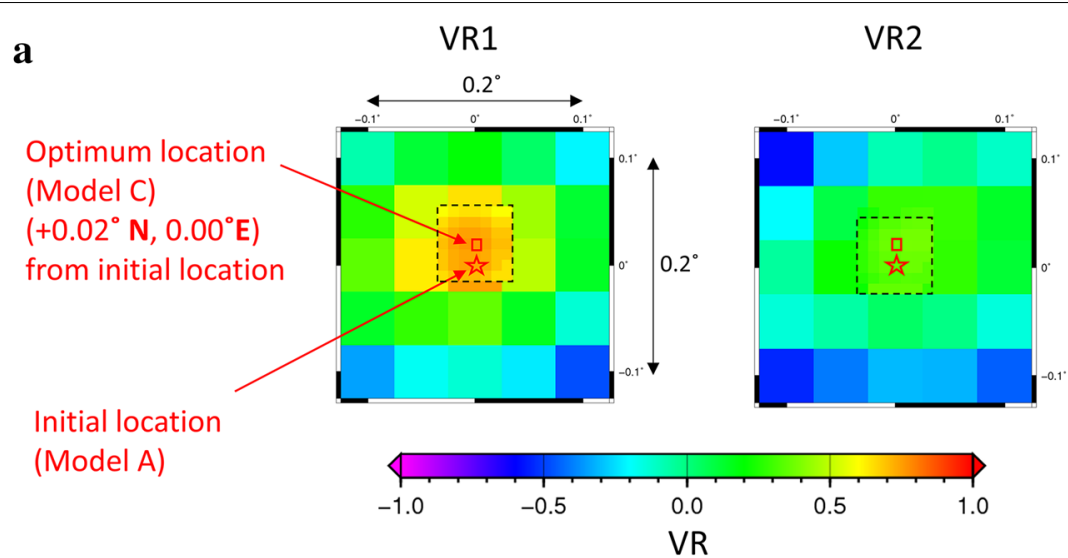

b

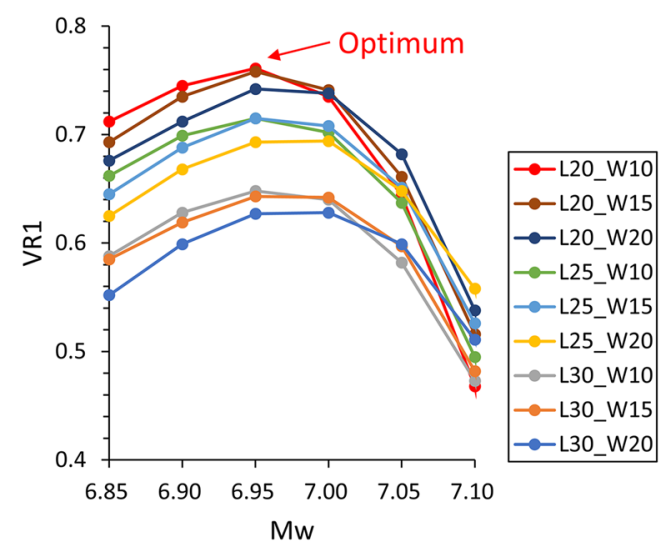

c

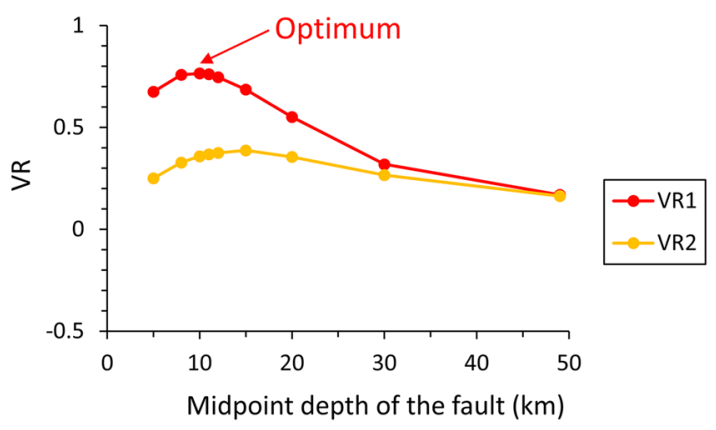

Fig. 6 Mean values of VR for model C after various parameters were changed from model A. a Changes in VR from shifting the horizontal location of model A (red star). The area within the dashed rectangle was searched in horizontal increments of $0.01^{\circ}$ to find the optimal location (red square). b VR1 versus $M w$ for various combinations of $L(\mathrm{~km})$ and $W(\mathrm{~km})$ in model C. c VR for various fault depths between 5 and $50 \mathrm{~km}$ in model C

In the comparison between the optimum single-fault model (model $\mathrm{C}$ ) and the FFM with horizontal shift (model D), the model C was superior to the model D with the smaller amplitude differences (Fig. 5b) and the VR values (Fig. 5d). The first reason for this is that the main slip region was concentrated in one place that the single-fault model could express. The second reason is that the slip distribution and slip amount of the FFM may have not been strictly represented due to estimation errors in the seismological analysis, while there was no limitation on fault parameters of the optimum single-fault model to fit the observed tsunami waveforms.

\section{Uncertainty of horizontal location from seismic data}

The optimum single-fault model (model C) located about $10-20 \mathrm{~km}$ west from the centroid location of various institutions (Fig. 9). The FFM with horizontal shift (model D) also located $0.02^{\circ}$ to the north and $0.06^{\circ}$ to the west from the original FFM (model B). Both results show that the horizontal location was determined relatively poorly only from the seismic data. This may be related to the propagation speed difference between seismic and tsunami waves. Since this event occurred at the shallow depth, the speed of tsunami wave is particularly slow. While such location difference would not significantly affect the comparison of seismic waveforms, the same amount of location difference would cause recognizable tsunami waveform misfits.

\section{Comparison of models in this study and models from previous studies}

We compared the results of the optimum single-fault model (model C) and the FFM with horizontal shift (model D) and the tsunami inversion models of previous studies (Gusman et al. 2017a; the GCMT model of Adriano et al. 2018). The $M_{w}$ of the model C $\left(M_{w} 6.95\right.$ $\left.[\mu=30 \mathrm{GPa}] ; M_{w} 6.92[\mu=27 \mathrm{GPa}]\right)$ almost agrees with $M_{w} 7.0(\mu=27 \mathrm{GPa})$ of Gusman et al. (2017a) and $M_{w}$ $6.95(\mu=27 \mathrm{GPa})$ of Adriano et al. (2018). It is also consistent with the $M_{w} 6.9-7.0$ from the CMT solutions. The normalized root-mean-square misfit (Heidarzadeh et al. 

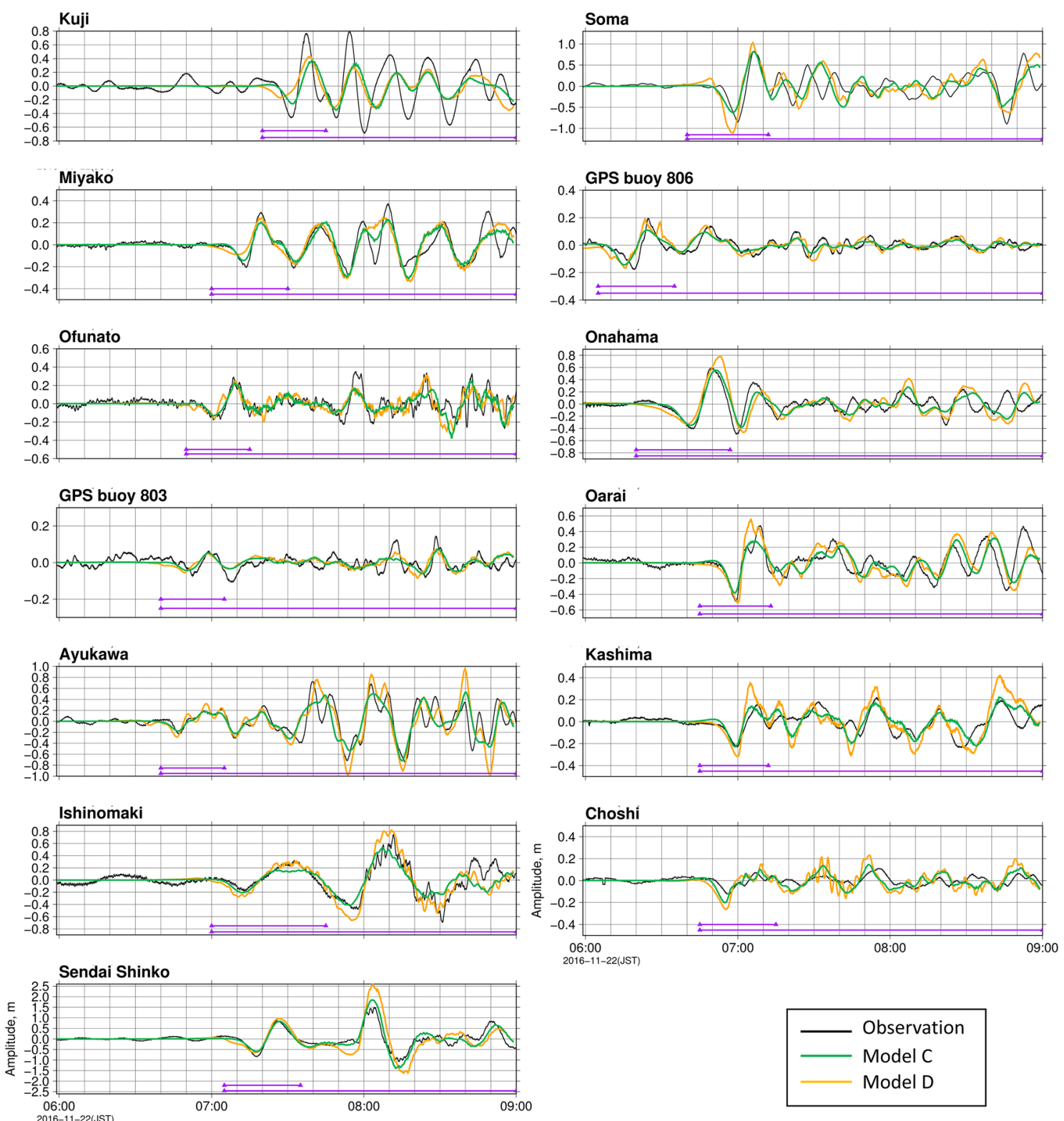

Fig. 7 Comparison of waveforms at 13 stations from observations, model C, and model D. Black curves are the observed waveforms, green curves are waveforms from model C, and orange curves are waveforms from model D. Data lengths for calculating VR1 and VR2 at each station are indicated by purple lines

2016) for the model $C$ was 0.75 for the same data period as the calculation of VR2, which is lower (better) than 0.85 in the prototype single-fault model (GCMT NP1) of Gusman et al. (2017a). The value only for Sendai Shinko was 0.47 , which was also lower (better) than 0.686 in the tsunami inversion model of Adriano et al. (2018). From the comparison with the figures shown in the papers, the single-fault model in this study has almost equivalent performance with Gusman et al. (2017a) and Adriano et al. (2018). This means that a simple model has the almost same performance as a complicated model in this event. The first reason for this is that the main slip region on the fault plane was concentrated in one place in this event; therefore, the single-fault model could express it. The second reason may be that the horizontal position of small sub-faults is fixed beforehand in the tsunami waveform inversion, while the horizontal position of the single-fault model can be freely moved at $0.01^{\circ}$ interval in this study. 


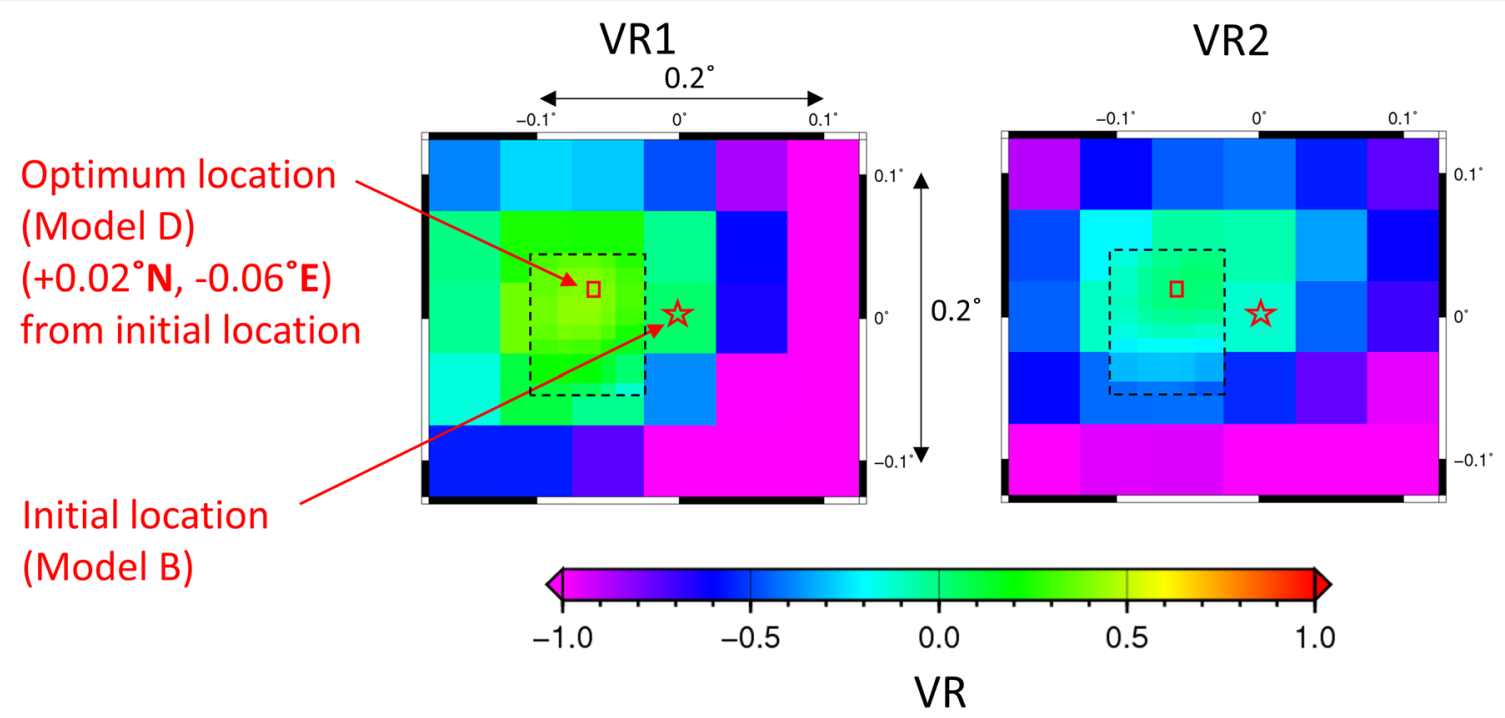

Fig. 8 Spatial distribution of mean values of VR for model D, the horizontally shifted version of model B. The color scale indicates the values of VR, and the spatial scale indicates the difference from the initial position. The initial shift from the location of model B (red star) was $0.05^{\circ}$; then the dashed rectangle was searched at increments of $0.01^{\circ}$ to find the optimal location (red square)

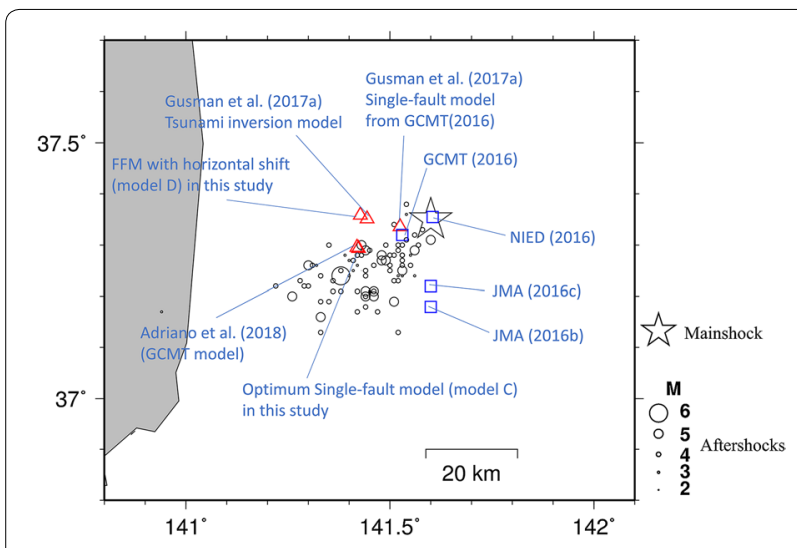

Fig. 9 Comparison of horizontal locations. Red triangles show the horizontal locations of the negative peak of the initial sea surface displacement for each model. The horizontal locations were measured by the figure of Gusman et al. (2017a), Adriano et al. (2018) and this study. The centroid locations of each institution are also shown with blue squares

Figure 9 shows the horizontal locations of the negative peak of the initial sea surface displacement for various models. The location of the model D in this study is close to that of Gusman et al. (2017a); and the location of the model C is close to that of Adriano et al. (2018). The location of the model $C$ is located about $10 \mathrm{~km}$ south-southwest of that of the model D. The location of the model $\mathrm{C}$ would be more plausible since it can express the tsunami waveforms better than the model D (Fig. 5d). The location difference between the Gusman et al. (2017a) and the Adriano et al. (2018) may be due to the difference of the number of sub-faults and locations.

\section{Summary}

We compared the performance of five models: the seismologically deduced single-fault model based on the CMT solution, the seismologically deduced FFM, the optimum single-fault model with tsunami data, the FFM with horizontal shift, and the tsunami waveform inversion models of the previous study for the earthquake off Fukushima Prefecture on 22 November 2016, Japan. We compared the models with the amplitudes, the period, and the VR, and obtained results as:

1. The seismologically deduced FFM has an advantage in terms of the information of slip regions of fault plane and was superior to the seismologically deduced single-fault model, especially in predicting amplitudes of tsunami. When only with seismic data, the FFM could narrow the range of forecast of tsunami amplitude.

2. The optimized single-fault model with tsunami data has performance to represent the observed tsunami waveforms at 13 stations well. It is better than the prototype single-fault model of Gusman et al. (2017a) and has the almost equivalent performance with the tsunami waveform inversion models of Adriano et al. (2018). The horizontal location of its negative peak of the initial sea surface displacement located close to that of Adriano et al. (2018) rather than that by the centroid location of CMT solution. In case the main 
generation region of the tsunami is concentrated in one place like this event, the tsunami wave can be expressed by a single-fault model by conducting the detailed grid search.

3. The centroid location of CMT solution and the absolute location of the FFM were not necessarily proper enough to get good agreement between observed and computed tsunami waves, while the $M w$, the focal mechanism, the centroid depth of CMT solution, and the relative slip distribution of a seismologically deduced FFM were effective to represent tsunami wave reproduction. This may be due to difference in the propagation speeds between seismic wave and tsunami wave. Since this event occurred at the shallow depth, the speed of tsunami wave is particularly slow. To utilize the analysis of seismic waves in tsunami forecasting, careful attention should be paid to its horizontal uncertainty, especially when a tsunami occurs in shallow water.

\begin{abstract}
Abbreviations
FFM: finite fault slip model; GCMT: the Global Centroid Moment Tensor Project; JMA: the Japan Meteorological Agency; NIED: the National Research Institute for Earth Science and Disaster Resilience; USGS: the US Geological Survey; VR: variance reduction; VR1:VR for the first wave cycle; VR2:VR for the data period from the first wave arrival to 9:00 JST on 22 November 2016.
\end{abstract}

\section{Authors' contributions}

KN proposed the initial idea of this study, conducted the analyses and drafted the manuscript. YH made suggestions about the organization and method of the article. HT supported the tsunami computation and the evaluation of the results. KF gave advice on using the FFM. YY gave advice on using the FFM and supported the manuscript preparation. AK made suggestions about the organization of the article and supported the manuscript preparation. All authors read and approved the final manuscript.

\section{Author details \\ ${ }^{1}$ Meteorological Research Institute, Japan Meteorological Agency, 1-1 Nagamine, Tsukuba, Ibaraki 305-0052, Japan. ${ }^{2}$ Ministry of Education, Culture, Sports, Science and Technology, 3-2-2 Kasumigaseki, Chiyoda-ku, Tokyo 100-8959, Japan. ${ }^{3}$ Seismology and Volcanology Department, Japan Meteorological Agency, 1-3-4 Otemachi, Chiyoda-ku, Tokyo 100-8122, Japan. ${ }^{4}$ Meteorological College, Japan Meteorological Agency, 7-4-81 Asahi, Kashiwa,} Chiba 277-0852, Japan.

\section{Acknowledgements}

Records from tide gauge stations and GPS buoys were provided by the Port Authority of the Ministry of Land, Infrastructure, Transport and Tourism, the Geospatial Information Authority of Japan website (http://tide.gsi.go.jp/ main.php?number=18), and the Japan Meteorological Agency. We used the TUNAMI code developed by Tohoku University as a tsunami computing simulation code, with input/output modifications by the Meteorological Research Institute. Topographical data were provided by the Cabinet Office Central Disaster Management Council, which are also available on the website (http://www.bousai.go.jp/kaigirep/chuobou/senmon/nihonkaiko_chisimajis hin/index.html). Parts of the figures were created with Generic Mapping Tools (Wessel and Smith 1998). We thank Editor Stephen Bannister and two anonymous reviewers for their thorough reviews and valuable suggestions on improving the quality of this article.

\section{Competing interests}

The authors declare that they have no competing interests.

\section{Availability of data and materials}

Not applicable.

\section{Consent for publication}

Not applicable.

Ethics approval and consent to participate

Not applicable.

\section{Funding}

Not applicable.

\section{Publisher's Note}

Springer Nature remains neutral with regard to jurisdictional claims in published maps and institutional affiliations.

Received: 1 November 2018 Accepted: 1 March 2019

Published online: 11 March 2019

\section{References}

Adriano B, Fujii Y, Koshimura S (2018) Tsunami source and inundation features around Sendai Coast, Japan, due to the November 22, 2016 Mw 6.9 Fukushima earthquake. Geosci Lett 5:2. https://doi.org/10.1186/s4056 2-017-0100-9

Aki K (1966) Generation and propagation of $G$ waves from the Niigata Earthquake of June 16, 1964: part 2. Estimation of earthquake moment, released energy, and stress-strain drop from the $\mathrm{G}$ wave spectrum. Bull Earthq Res Inst 44:73-88

Cabinet Office (2003) Expert study group on subduction zone earthquake around Japan trench and Chishima trench. http://www.bousai.go.jp/kaigi rep/chuobou/senmon/nihonkaiko_chisimajishin/index.html. Accessed 17 July 2018 (in Japanese)

Dziewonski AM, Anderson DL (1981) Preliminary reference Earth model. Phys Earth Planet Inter 25:297-356. https://doi.org/10.1016/00319201(81)90046-7

Fujii Y, Satake K (2016) Off-Fukushima Tsunami on Nov. 21, 2016. http://iisee .kenken.go.jp/staff/fujii/Fukushima2016/tsunami.html. Accessed 17 July 2018

Global Centroid-Moment-Tensor Project (2016) http://www.globalcmt.org/. Accessed 27 Dec 2016

Goto C, Ogawa Y, Shuto N, Imamura F (1997) Numerical method of tsunami simulation with the leap-frog scheme in IUGG/IOC TIME Project IOC Manual and Guides. UNESCO, Paris

Gusman AR, Satake K, Shinohara M, Sakai S, Tanioka Y (2017a) Fault slip distribution of the 2016 Fukushima earthquake estimated from tsunami waveforms. Pure Appl Geophys 174:2925-2943. https://doi.org/10.1007/ s00024-017-1590-2

Gusman AR, Satake K, Harada T (2017b) Rupture process of the 2016 Wharton Basin strike-slip faulting earthquake estimated from joint inversion of teleseismic and tsunami waveforms. Geophys Res Lett 44:4082-4089. https://doi.org/10.1002/2017GL073611

Headquarters For Earthquake Research Promotion, Ministry of Education, Culture, Sports, Science and Technology (2016) Monthly Reports on Evaluation of Seismic Activities in Japan. https://www.static.jishin.go.jp/resou rce/monthly/2016/2016_11.pdf. Accessed 17 July 2018 (in Japanese)

Heidarzadeh M, Murotani S, Satake K, Ishibe T, Gusman AR (2016) Source model of the 16 September 2015 Illapel, Chile, Mw 8.4 earthquake based on teleseismic and tsunami data. Geophys Res Lett 43:643-650. https:// doi.org/10.1002/2015GL067297

Heidarzadeh M, Murotani S, Satake K, Takagawa T, Saito T (2017) Fault size and depth extent of the Ecuador earthquake (Mw 7.8) of 16 April 2016 from teleseismic and tsunami data. Geophys Res Lett 44:2211-2219. https:// doi.org/10.1002/2017GL072545 
Imamura F (1995) Review of tsunami simulation with a finite difference method. In: Yeh H, Liu P, Synolakis C (eds) Long-wave runup models. World Scientific, Singapore, pp 25-42

Iwakiri K, Kawazoe Y, Hasegawa Y (2014) Source process analysis performed by Japan Meteorological Agency using seismic waveforms - analysis method and scaling relationships derived from fault slip distributions. Q J Seismol 78:65-91 (in Japanese with English abstract and figure captions)

Japan Meteorological Agency (2016a) Monthly report on earthquakes and volcanoes in Japan November 2016. http://www.data.jma.go.jp/svd/ eqev/data/gaikyo/monthly/201611/201611index.html. Accessed 17 July 2018 (in Japanese)

Japan Meteorological Agency (2016b) Focal mechanism solution of major earthquakes (preliminary report). http://www.data.jma.go.jp/svd/eew/ data/mech/top.html. Accessed 23 Nov 2016 (in Japanese)

Japan Meteorological Agency (2016c) CMT solutions for earthquakes in November, 2016. http://www.data.jma.go.jp/svd/eqev/data/mech/pdf/ cmt201611.pdf. Accessed 17 July 2018

Japan Meteorological Agency (2017a) Evaluation of tsunami warning etc. on the earthquake off Fukushima Prefecture on 22 November 2016, study session on tsunami prediction technology. http://www.data.jma. go.jp/svd/eqev/data/study-panel/tsunami/benkyokai14/shiryou2-2.pdf. Accessed 17 July 2018 (in Japanese)

Japan Meteorological Agency (2017b) Results of source process analysis of remarkable earthquakes occurring in Japan. http://www.data.jma.go.jp/ svd/egev/data/sourceprocess/index.html. Accessed 5 Jan 2018 (in Japanese)

Kamigaichi O (2015) Tsunami forecasting and warning. In: Meyers R (ed) Encyclopedia of complexity and systems science. Springer, Heidelberg, pp 1-38. https://doi.org/10.1007/978-3-642-27737-5_568-3

Kanamori H (1977) The energy release in great earthquakes. J Geophys Res $82: 2981-2987$

Kato T, Terada Y, Kinoshita M, Kakimoto H, Isshiki H, Matsuishi M, Yokoyama A, Tanno T (2000) Real-time observation of tsunami by RTK-GPS. Earth Planets Space 52:841-845. https://doi.org/10.1186/BF03352292

Kawai H, Satoh M, Kawaguchi K, Seki K (2012) Recent tsunamis observed by GPS buoys off the Pacific coast of Japan. In: Proceedings of the 33rd Conference on Coastal Engineering, ASCE, pp 47-61

Kikuchi M (2003) Real-time seismology. University of Tokyo Press, Tokyo (in Japanese)
Mansinha L, Smylie DE (1971) The displacement field of inclined faults. Bull Seismol Soc Am 61:1433-1440

Murakami K (1981) The harmonic analysis of tides and tidal currents by least square method and its accuracy. Technical note of the port and harbor research institute Ministry of transport Japan 369 (in Japanese with English abstract)

National Research Institute for Earth Science and Disaster Resilience (2016) Earthquake mechanism information. http://www.fnet.bosai.go.jp/event/ tdmt.php?_id=20161121205800.NO1\&LANG=en Accessed 17 July 2018

Suppasri A, Yamashita K, Latcharote P, Roeber V, Hayashi A, Ohira H, Fukui K, Hisamatsu A, Imamura F (2017) Numerical analysis and field survey of the 2016 Fukushima earthquake and tsunami. J Jpn Soc Civ Eng Ser B2 Coast Eng 73(2):1597-1602. https://doi.org/10.2208/kaigan.73.i_1597 (in Japanese with English abstract)

Tanioka Y, Miranda GJA, Gusman AR, Fujii Y (2017) Method to determine appropriate source models of large earthquakes including tsunami earthquakes for tsunami early warning in Central America. Pure Appl Geophys 174:3237-3248. https://doi.org/10.1007/s00024-017-1630-y

Toda and Goto (2016) Identification of the active fault that caused the earthquake off Fukushima Prefecture (M7.4) on November 22. http://iride s.tohoku.ac.jp/media/files/earthquake/eq/2016_fukushima_eq/20161 122_fukushima_eq_activefault_toda.pdf. Accessed 30 Nov 2016 (in Japanese)

Tsushima H, Hino R, Fujimoto H, Tanioka Y, Imamura F (2009) Near-field tsunami forecasting from cabled ocean bottom pressure data. J Geophys Res 114:B06309. https://doi.org/10.1029/2008JB005988

U.S. Geological Survey (2016) M 6.9-35 km ESE of Namie, Japan. https://earth quake.usgs.gov/earthquakes/eventpage/us10007b88\#moment-tensor. Accessed 17 July 2018

Usui Y, Aoki S, Hayashimoto N, Shimoyama T, Nozaka D, Yoshida T (2010) Description of and advances in automatic CMT inversion analysis. Q J Seismol 73:169-184 (in Japanese with English abstract and figure captions)

Utsu T (2001) Seismology, 3rd edn. Kyoritsu Shuppan, Tokyo (in Japanese)

Wessel P, Smith WHF (1998) New, improved version of the Generic Mapping Tools released. EOS Trans AGU 79:579

Yoshida Y, Ueno H, Muto D, Aoki S (2011) Source process of the 2011 off the Pacific coast of Tohoku Earthquake with the combination of teleseismic and strong motion data. Earth Planets Space 63:10. https://doi. org/10.5047/eps.2011.05.011

\section{Submit your manuscript to a SpringerOpen ${ }^{\odot}$ journal and benefit from:}

- Convenient online submission

- Rigorous peer review

- Open access: articles freely available online

- High visibility within the field

- Retaining the copyright to your article

Submit your next manuscript at $\boldsymbol{\nabla}$ springeropen.com 